\title{
Sepse após Trauma Contuso: Relato de Caso
}

Carla de Araújo Kern ${ }^{1}$, Jamila Albarello ${ }^{2}$, Francieli Galvan Corso ${ }^{3}$, Flaviana Fioreze Schenkel.

\section{Resumo}

INTRODUÇÃO: O Trauma contuso geralmente é resultante do impacto do corpo contra uma superfície, ou de um processo de desaceleração intensa e rápida. São provocados por acidentes automobilísticos, quedas, agressões, traumas esportivos. A maioria dos casos tem boa evolução e recuperação, porém alguns podem levar o paciente a óbito. A sepse, embora rara, é uma das complicações apresentadas por pacientes vítimas de trauma contuso. A sepse é causada pela resposta inflamatória sistêmica descontrolada do indivíduo na presença de infecção, associada a duas ou mais das condições: temperatura $>38^{\circ} \mathrm{C}$ ou $<36^{\circ} \mathrm{C}$; FC $>90 \mathrm{bpm}$; FR $>20$ ipm ou $\mathrm{PaCO} 2<32$ $\mathrm{mmHg}$; contagem de glóbulos brancos $>12.000 / \mathrm{mm} 3 \mathrm{ou}<4.000 \mathrm{~mm} 3 \mathrm{ou}$ bastonetes $>10 \%$.

RELATO DE CASO: LA, 18 anos, natural e procedente de Praia Grande SC, vítima de trauma contuso em coxa direita no durante jogo de futebol. Dois dias após dirigiu-se ao Hospital de Praia Grande-SC, com queixa de dor difusa, do tipo latejante, em MID, onde foi internado e medicado com antiinflamatório.Recebeu alta hospitalar no mesmo dia. No dia seguinte voltou ao serviço onde foi internado, pois estava apresentando dificuldade de deambulação, edema, sinais flogisticos no local do trauma e febre. Foi medicado com analgésicos e permaneceu em observação. No $4^{\circ}$ dia após o trauma, foi transferido para o HSJ onde foi diagnosticado com sepse após trauma contuso. Encaminhou-se o paciente para UTI, no $2^{\circ}$ dia de internação evoluiu com trombose venosa profunda, em veia femoral e poplítea, porção proximal da veia tibial posterior e também de veias gastrocnêmicas. Nesse momento paciente apresentava edema de +++ , eritema extenso, lesão 
enegrecida extensa, flictemas e pulsos palpáveis. Relata-se evolução para IRA pré-renal. No $4^{\circ}$ dia de internação, devido a não melhora do quadro, optou-se por debridamento da lesão, para ver se existiria melhora da lesão extensa e da função renal. Após 36 horas do procedimento a equipe de cirurgia vascular optou por amputação do MID a nível de coxa e com isso melhora dos demais sintomas.

CONCLUSÃO: A sepse em trauma contuso, esporádica em nosso meio, deve ser diagnosticada e tratada precocemente devido a sua rápida progressão para o choque, falência orgânica ou óbito. O acompanhamento multidisciplinar é de extrema importância, visando à boa recuperação e à readaptação funcional do paciente.

PEREIRA JÚNIOR, Gerson Alves et al. FISIOPATOLOGIA DA SEPSE E SUAS IMPLICAÇÕES TERAPÊUTICAS. Medicina (Ribeirao Preto. Online), Brasil, v. 31, n. 3, p. 349-362, sep. 1998. ISSN 2176-7262. Disponível em: $\langle$ http://www.revistas.usp.br/rmrp/article/view/7681 >. Acesso em: 06 mar. 2016. doi:http://dx.doi.org/10.11606/issn.2176-7262.v31i3p349-362.

Meirelles, S. S. L., et al. "Traumatismo arterial de membros inferiores." Angiologia e cirurgia vascular: guia ilustrado. Maceió: UNCISAL/ECMAL \& LAVA (2003). 